\title{
Potential of Extremophiles for Biotechnological and Petroleum Applications
}

\author{
M. S. A. TANGO \\ M. R. ISLAM \\ Department of Civil Engineering \\ Dalhousie University \\ Halifax, Canada
}

\begin{abstract}
The ability of microorganisms to survive under harsh conditions has recently prompted researchers to study these microbes to better understand their characteristics and eventually utilize them in various applications. Extremophilic microorganisms withstand one or more extreme condition constraints due to cold, heat, high acidity, high alkalinity, high salinity, and high pressure levels. These constraints would destroy normal microorganisms. Extremophiles can be classified according to the environment in which they survive. Many extremophilic microorganisms possess properties suitable for biotechnological and commercial uses. This article discusses the characteristics and future potentials of extremophiles.
\end{abstract}

Keywords biotechnological, biohydrometallurgy, extromophiles, extromozymes, growth environments, heavy metal recovery, petroleum containment

\section{Introduction}

Over the last two decades, scientists have been intrigued by the microbes that thrive in extreme environments. The microorganisms that have the ability to resist or withstand extreme environmental conditions are known as extremophiles. Extremophiles may be divided into 5 categories - thermophiles (high temperature), acidophiles (low pH), alkaliphiles (high pH), halophiles (high salinity), and psychrophiles (low temperature)clearly indicating the nature of the habitats favored by these microbes.

These habitats include hot springs, shallow submarine hydrothermal systems, or hot-vent systems, where microorganisms can be found at temperatures above $100^{\circ} \mathrm{C}$. Extremophiles are also found in highly saline lakes or salterns, sometimes at salt conditions near that of saturation, and in environments with extreme $\mathrm{pH}$ values, either acidic (acidic fields and acidic sulfur pyrite areas) or alkaline (freshwater, alkaline hot springs, carbonate springs, alkaline soils, and soda lakes). The sources of psychrophilic organisms include the cold polar seas and soils and Alpine glaciers, as well as deep-sea sediments, which are cold and are also at high pressures. Figures 1-4 illustrate images of extremophilic organisms found in deep ocean (about $3.7 \mathrm{~km}$ below the ocean surface) environments. Often extremophiles live in situations combining several stress factors, for instance, a high temperature and acidic conditions or a high pressure and low $\mathrm{pH}$ conditions.

Received 4 June 2001; accepted 12 July 2001.

Address correspondence to Dr. R. Islam, Department of Civil Engineering, Dalhousie University, 1360 Barrington Street, Halifax, Canada, NS B3J 2X4. E-mail: Rafiqul.Islam@ dal.ca 


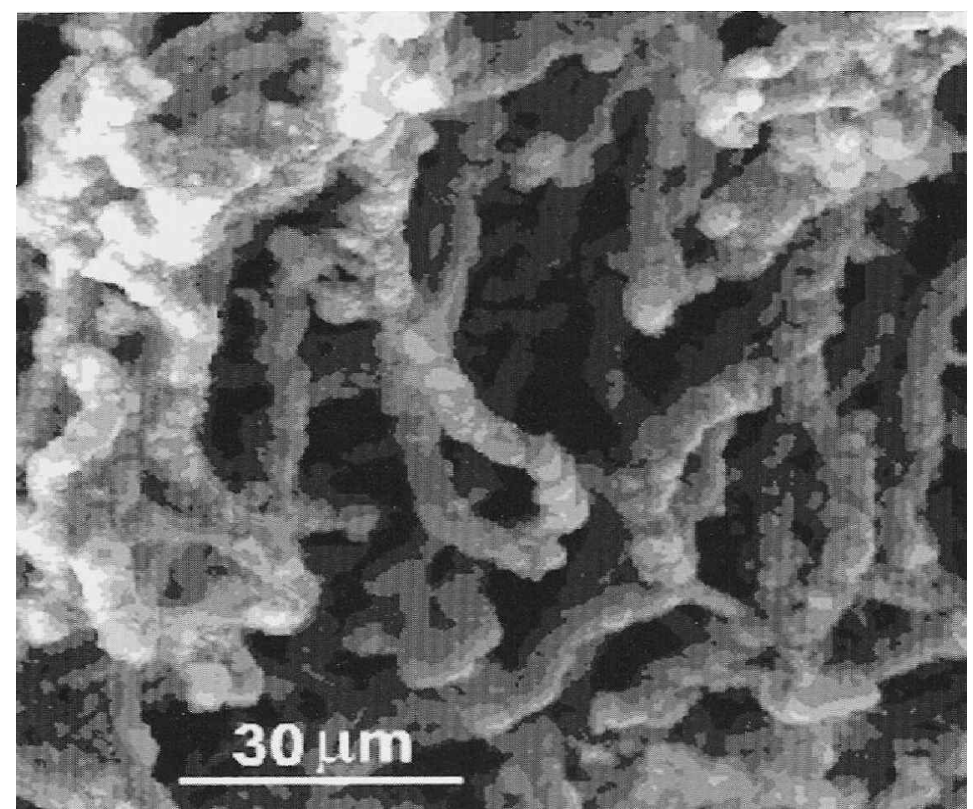

Figure 1. Environmental scanning electron microscopy (ESEM) showing chains of cocci bacteria (extremophiles) detected in the rusticles. (Courtesy: Wells and Mann, 1997.)

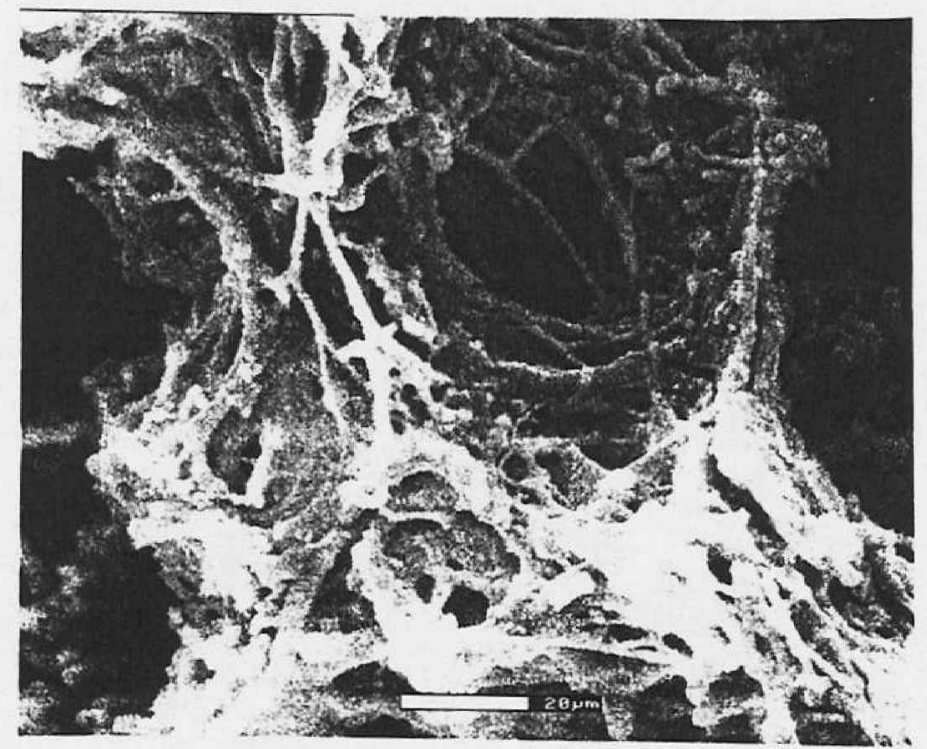

Figure 2. Filamentous (Leptothrix sp.) extremophilic bacteria in the rusticles formed basket-shaped structures. (Courtesy: Wells and Mann, 1997.) 


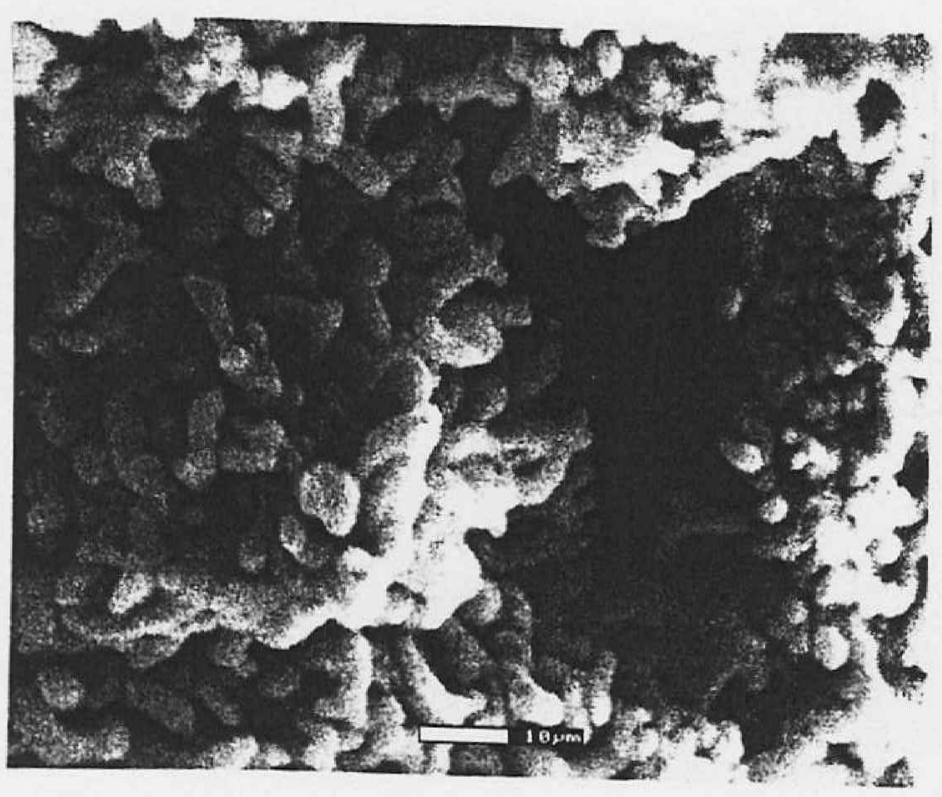

Figure 3. Image showing aggregation of mineralized coccoidal bacteria (extremophiles) embedded in the rusticle. (Courtesy: Brown, 1997.)

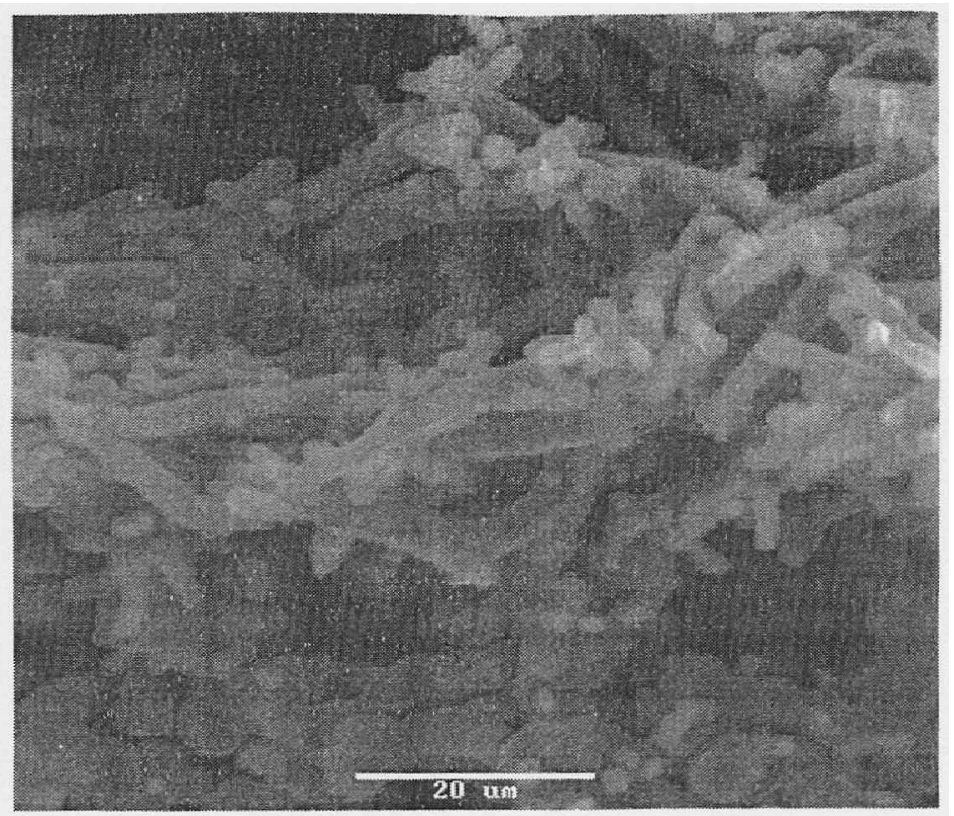

Figure 4. A mass of rod-shaped extremophiles embedded in the rusticle forming a helix-like structure. (Courtesy: Brown, 1997.) 


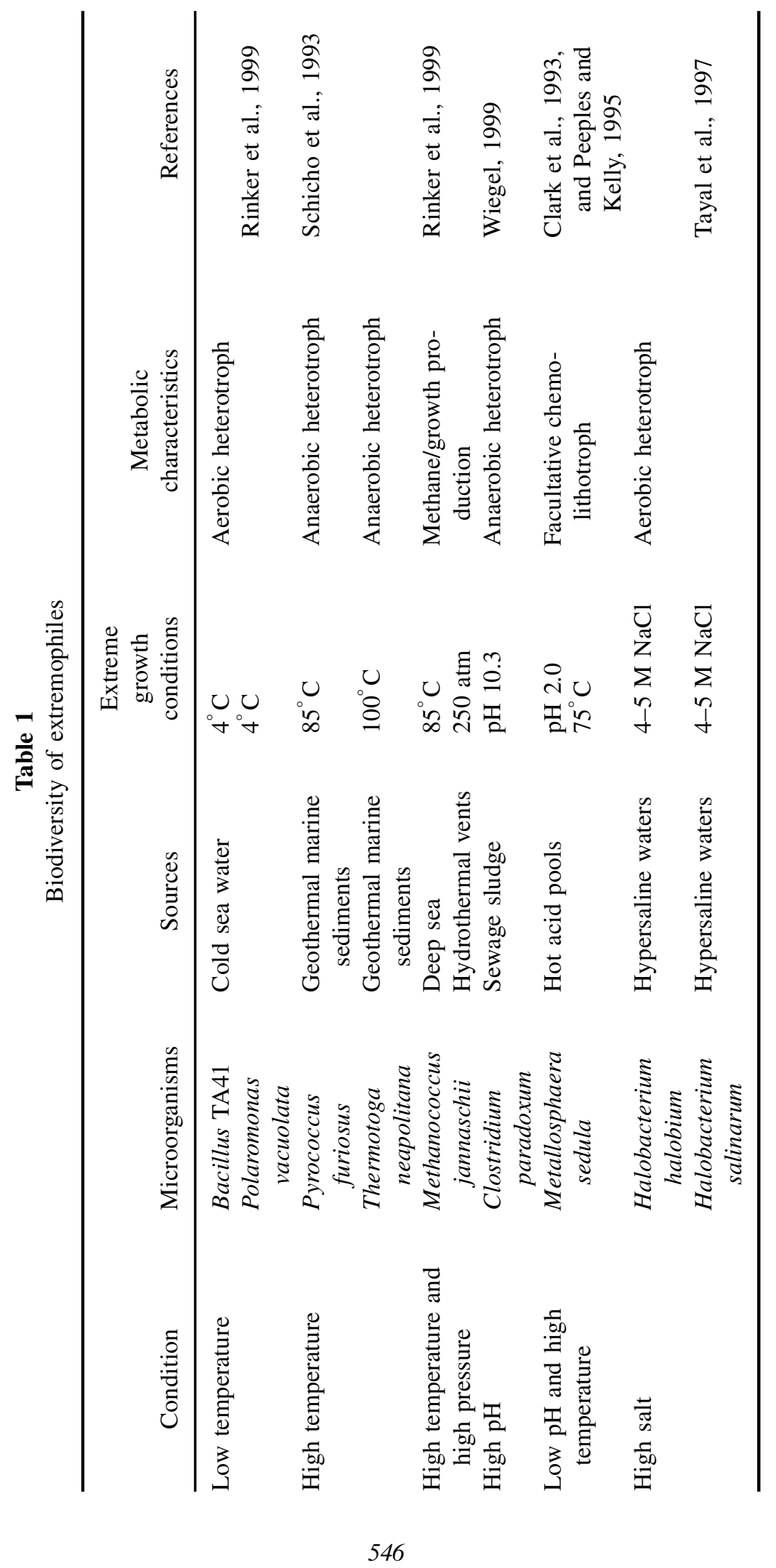


These instances suggest that wherever there is an extreme environment, there are very likely to be extremophiles. Table 1 shows the diversity of some extremophiles.

The ability of microorganisms to survive under harsh conditions has recently prompted researchers to study these organisms to better understand their characteristics and eventually utilize them in various applications. Many extremophilic microorganisms possess properties suitable for biotechnological and commercial uses.

This paper reviews the pertinent role of extremophiles and their potential in biotechnological and petroleum industries.

\section{Growth Environments}

\section{Cold Environments}

Cold environments are often more common than hot ones. More than half of the earth's surface is ocean and has an average temperature of $1-3^{\circ} \mathrm{C}$. The majority of land areas in the Arctic and Antarctic are permanently frozen and are thawed for only a few weeks during summer. These areas are favored by and support the life of psychrophile microbes.

Some studies have reported on microbial communities in Antarctic sea ice-ocean water that remains frozen for much of the year (Irgens et al., 1996; Rinker et al., 1999). These communities include photosynthetic eukarya, algae, and diatoms, as well as a variety of bacteria. One specie of bacterium found was Polaromonas vacuolata, a typical representative of a psychrophile. Its optimal temperature for growth is $4^{\circ} \mathrm{C}$, and temperatures above $12^{\circ} \mathrm{C}$ were found to be too warm for reproduction. Cold-loving organisms have started to interest manufacturers for the development of enzymes that work at refrigerator temperatures. Food processing companies whose products often require cold temperatures to avoid spoilage, producers of fragrances that evaporate at high temperatures, and manufacturers of cold-wash laundry detergents are the potential beneficiaries of this group of microbes.

\section{Acidic Environments}

The majority of natural environments on the earth are essentially neutral, having $\mathrm{pH}$ values between 5 and 9. Acidophiles survive in the habitats having a $\mathrm{pH}<5$ and at temperatures between 50 and $79^{\circ} \mathrm{C}$ (Brock et al., 1972). These organisms are the subject of increasingly intense studies due to their potential for in situ metal leaching of geothermally heated ore deposits. Clark et al. (1993) observed highly efficient ore-leaching capabilities using Metallosphaera sedula.

Highly acidic environments can result naturally from geochemical activities such as the production of sulfurous gases in hydrothermal vents, some hot springs, and the metabolic activities of certain acidophiles themselves (Peeples and Kelly, 1995). Acidophiles are also found in the debris left over from coal mining. Apparently, acidophiles cannot tolerate great acidity inside their cells, where it would destroy important molecules such as DNA. They survive by keeping the acid out. The molecules that protect the cell, as well as others that come into contact with the environment, must be able to operate in extreme acidity. Indeed, extremozymes that are able to work at a $\mathrm{pH}$ below 1 , more acidic than even vinegar or stomach fluids, have been isolated from the cell wall and underlying cell membrane of some acidophiles.

Potential applications of acid-tolerant extremozymes range from catalysts for the synthesis of compounds in an acidic solution to additives for animal feed, which are intended to work in the stomachs of animals. The enzymes that are selected are those 
that microbes usually secrete into the environment to break food into sizes suitable for ingestion. When added to feed, these enzymes improve the digestibility of inexpensive grains, thereby avoiding the need for more expensive food.

\section{Alkaline Environments}

Alkaliphiles live in soils rich with carbonates and in so-called soda lakes, such as those found in Africa (such as Egypt and the Rift Valley in Kenya and Tanzania) and the western U.S. At a pH above 8, certain molecules, especially those made of ribonucleic acid (RNA), break down. Alkaliphiles, just like acidophiles, maintain neutral $\mathrm{pH}$ in their interior, and their extremozymes are located on or near the cell surface and in external secretions. This feature makes alkaliphiles suitable for producing detergents. Manufacturers of detergents in the U.S. and Japan are particularly excited by alkaliphilic enzymes. The Horikoshi group at Japan Marine Science and Technology has embraced extremozymes with enthusiasm and pioneered the research into alkaliphilic extremozymes (Horikoshi, 1999).

To work effectively, detergents must be able to cope with stains from food and other sources of grease. This task can easily be accomplished by such enzymes as proteases (protein degraders) and lipases (grease degraders). However, laundry detergents tend to be highly alkaline and thus destructive to standard proteases and lipases. Alkaliphilic versions of these enzymes can solve the problem, and several types that can operate efficiently in heat or cold are now in use or being developed. Alkaliphilic extremozymes are also earmarked to replace standard enzymes that produce better aesthetics on fabric. Over the past 2 decades, many studies have focused on the enzymology, physiology, ecology, taxonomy, molecular biology, and genetics of alkaliphilic microorganisms to establish a new microbiology of alkaliphilic microbes (Horikoshi, 1999).

\section{Saline Environments}

The group of halophilic extremophiles inhabit highly saline environments, especially natural salt lakes and solar salt evaporation ponds. The solar salt ponds are constructed pools where seawater collects and evaporates, leaving behind high concentrations of salt that can be harvested and utilized as deicing and antiicing agents. Some saline environments are also extremely alkaline, due to weathering of sodium carbonate, and certain other salts can release ions that produce alkalinity. In such cases, microorganisms in these environments are adapted to both high alkalinity and high salinity.

Halophiles are able to live in salty conditions through a fascinating adaptation. Because water tends to flow from areas of high solute concentration to areas of lower concentration, a cell suspended in a very salty solution will lose water and become dehydrated unless its cytoplasm contains a higher concentration of salt (or some other solute) than its environment. Halophiles contend with this problem by producing large amounts of an internal solute or by retaining a solute extracted from outside (Garabito et al., 1998). For instance, an archaean known as Halobacterium salinarum concentrates potassium chloride in its interior. As might be expected, the enzymes in its cytoplasm will function only if a high concentration of potassium chloride is present, but proteins in Halobacterium salinarum cell structures that are in contact with the environment require a high concentration of sodium chloride.

The potential applications for salt-tolerant enzymes are steadily growing, following the trends for other extremozymes. For example, investigators are now exploring incorporating halophilic extremozymes into procedures used to increase the amount of crude 
extracted from oil wells. Tayal et al. (1997) reported promising laboratory tests through enzymatic hydrolysis of this aspect while studying the viscosity of hydraulic fracturing fluids.

Scientists rarely find large quantities of a single species of microbe in nature. A desired organism must be purified, usually by isolating single cells, and then grown in a laboratory culture. For organisms with extreme lifestyles, isolation and large-scale production can prove both difficult and expensive.

\section{Harvesting Extremozymes}

Fortunately, extremozymes can be produced through recombinant DNA technology without massive culturing of the source extremophiles (Adams and Kelly, 1998). Genes, which consist of DNA, specify the composition of the enzymes and other proteins made by cells. These proteins carry out most cellular activities. As long as microbial prospectors can obtain sample genes from extremophiles in nature or from small laboratory cultures, they can generally clone those genes and use them to make the corresponding proteins. That is, by using the recombinant DNA technologies, they can insert the genes into ordinary, or domesticated, microbes, which will often use the genes to produce unlimited, pure supplies of the enzymes (Robertson et al., 1996).

Two approaches have been exploited to identify potentially valuable extremozymes. The more traditional route requires scientists to grow at least small cultures of an extremophile obtained from a particular environment. For instance, if the scientists are interested in protein-degrading enzymes, they test to see whether extracts of the cultured cells break down selected proteins. Once the activity is detected, the scientists resort to standard biochemical methods to isolate the enzymes responsible for the activity and to isolate the genes encoding the enzymes. They then must hope that the genes can be induced to produce their corresponding proteins in a host gene.

In the other approach, researchers avoid growing any cultures of extremophiles. They isolate the DNA from all living things in a sample of water, soil, mud, rocks, or other material from an extreme environment. Then, using recombinant DNA technology once again, they deliver random stretches of DNA into a domesticated host. Often they perform one insert per host cell without knowing the identities of the genes in those fragments. Eventually they screen the colonies that grow out, looking for evidence of activity by new novel enzymes. If they find such evidence, they conclude that an inserted gene is responsible and that it will work in the domesticated host. In this way they avoid many bottlenecks in the traditional process. Thus scientists can extract the genes for the enzymes from mixed populations of microbes without needing to culture extremophiles that might have trouble growing outside their native habitat.

Although the microbial world is diverse, scientists rarely succeed in extracting the perfect enzyme for a particular task. Therefore the leading scientists of industrial enzyme technology have begun to modify extremozymes, tailoring them to meet specific needs. For example, after finding an extremozyme that degrades proteins fairly efficiently at high temperatures, researchers might modify the enzyme so that it functions across a wider range of acidity and salinity. So far most extremozymes in commercial use are altered little from their original state. But the enzyme modification approaches promise to enhance extremozymes. They may also help to convert enzymes from ordinary microbes into artificial extremozymes.

Discovery of extremophiles opens new opportunities for the development of enzymes having superior catalytic capabilities. However, for any new enzyme to gain commercial 
acceptance, its producers will have to reduce the costs of production. In addition, they have to ensure that the domesticated microbes used as sources of extremozymes will reliably generate large quantities of the protein. The difficulties of perfecting manufacturing techniques, and the reluctance of industries to change systems that already work reasonably well, could slow the entry of new extremozymes into commerce. It seems inevitable, however, that their many advantages will eventually prove irresistible.

\section{Biotechnological Applications of Extremophiles}

\section{Extremozymes}

The use of extremophilic microorganisms in industrial processes has grown rapidly over the last 2 decades. Every category of these microbes has unique characteristics that can be harnessed for use in biotechnological industries. Enzymes from these microbes, namely extremozymes, possess high stability and reduced risk of contamination of the organisms that produce them. Other useful features of these enzymes during the production process include improved transfer rates and lower viscosity. Due to the superior properties of these enzymes, they are expected to form the bridge between biological and chemical processes (Adams and Kelly, 1998).

Recent developments of extremozymes indicate that they are good novel catalysts of great industrial interest (Adams and Kelly, 1995). Typical examples are polymerdegrading enzymes like amylases, proteases, cellulases, pullulanases, and xylanases. These enzymes have significant roles in chemical, food, pharmaceutical, paper, pulp, and waste-treatment industries (Adams et al., 1995). In the pharmaceutical industry, membranes of some extremophiles have been found to contain surfactants bearing a unique stability. Other important innovative products are cyclodextrins, compatible solutes, and polyunsaturated fatty acids.

\section{Heavy Metal Removal}

Heavy metal contamination is a problem in many environments as a result of increasing industrial activities. Currently, the risk associated with toxic heavy metals is not well known. Microorganisms can interact with heavy metals in a variety of ways that result in decreased metal mobility and solubility. Two biogeochemically important groups of microbes, the metal and sulfate-reducing bacteria, have suitable physiology for metal precipitation and immobilization. The activities of these microbes provide metabolic products such as iron and hydrogen sulfide, which lead to mineral formation. These minerals can react with heavy metals, forming precipitation and hence detoxification. Current understanding of how these microbes work is limited, and research has to be conducted to investigate how these metal and sulfate-reducing organisms behave in contaminated sites. In order to understand the removal of these toxins, we must explore the effects of heavy metals on the metabolism of anaerobic bacteria.

Toxic waste sites can poison or kill more commonly found organisms-those that require oxygen for survival. However, microbes that can live anaerobically (without oxygen) can tolerate the extreme conditions found in underground waste sites. Such microbes might be useful in keeping contamination from spreading away from already contaminated radioactive and metal-saturated soil. This application would be highly useful in many countries searching for ways to clean up contaminated soil. The research team led 
by T. C. Onstott of Princeton University went to the deep mines of the Transvaal region of South Africa looking for microbes that live at high temperatures and considerable pressures and that can handle an environment rich in uranium and organic carbon. The team found anaerobic microbes that survive in deep mine environments, possess high metal content, and have a higher than average amount of radiation. In particular, they were looking for microbes inhabiting an organic-rich vein that is highly mineralized, containing high concentrations of uranium and pyrite and one of the richest gold deposits in the world. The isolation process of extremophiles found in such areas need special attention. Rock samples were processed at the mine to remove the outer, potentially contaminated surfaces. Crushed rock fragments and groundwater collected from boreholes were used to inoculate the growth media in the sampling containers before the samples were added. The team also collected rock samples for further analyses on chemical and biological processes that occur around the microbes themselves, nucleic acids and membrane lipids, and to identify their types and metabolism.

Waste uranium in groundwater, streams, and ponds may be in the oxidized state and poses a potential health problem. Such uranium is soluble and mobile, increasing the risk of being spread into other areas. Regulatory guidelines require uranium to be confined to its sites, thus the need to change the chemical state of uranium. The main aim is to make uranium attach to soil, rocks, and stream sediments to ensure that it is retained on site. Bacteria (Shewanella putrefaciens $M R-1$ bacterium) that prevent uranium from dispersing into groundwater has been isolated (Palumbo and Zhou, 1996). This microbe is intriguing because it not only reduces metals (and thus is ideal for treating contaminated waters), but it also produces hydrogen and magnetite. Further studies on the genes from this microbial genome might be used to design microorganisms for advanced bioremediation of contaminated sites and streams. As a result, the uranium should precipitate out of the water, drop into the sediments, and remain within the confined site.

\section{Energy Production}

Biological hydrogen production is another interesting area. Extremozymes are also employed in the production of hydrogen gas. Hydrogen may be the fuel of the future once hydrogen fuel cells for propelling cars are perfected (McAlister, 1998). When oxygen and hydrogen are combined in a fuel cell, they provide electricity and a little heat, giving water as the only waste product. The hydrogen car will be clean because it will not discharge nitrogen oxides and carbon dioxide. Hydrogen can be obtained cheaply using special enzymes (extremozymes) by the transformation of cellulose into glucose sugar, then converting the glucose product and its byproduct, gluconic acid, into hydrogen (Woodward et al., 2000). The Woodward team has identified, isolated, purified, and characterized extremozymes that might be useful for bioprocessing and energy production.

The process of converting glucose to hydrogen is more efficient at higher temperatures, and thus it makes sense to replace some standard enzymes with extremozymes (hydrogenase). This hydrogenase is produced by the extremophile Pyrococcus furiosus, a strain of bacteria from a deep-sea hydrothermal vent (Raven et al., 1992). It works most efficiently at a temperature of $85^{\circ} \mathrm{C}$ and is also one of only two enzymes known to accept electrons from NADPH to produce hydrogen. Standard enzymes will stop working when exposed to higher temperatures unless special, costly measures are taken to protect these proteins. Some extremozymes might eliminate the need for protective steps, increasing efficiency and reducing costs. In addition, extremozymes may be more stable and react 
faster than their mesophilic counterparts. Similar studies in this field showed that hydrogen can be obtained enzymatically from other biomass substrates, such as lactose, sucrose, xylan, starch, and steam-exploded aspen wood (Miyamoto, 1997).

Biological hydrogen production is the most challenging area of biotechnology with respect to environmental problems. The future of biological hydrogen production depends not only on research advances, but also on economic considerations (the cost of fossil fuels), social acceptance, and the development of hydrogen energy systems.

\section{Compatible Solutes}

These are osmotically active substances that maintain the halophilic cell in positive water balances and are compatible with the cellular metabolism. They have low molecular weight and are highly water-soluble sugars, alcohols, amino acids, and their derivatives (Galinski, 1995; Ventosa et al., 1998). Compatible solutes are increasingly being utilized in biotechnological applications as stabilizers of biomolecules (DNA, enzymes, and membranes) and whole cells or as stress-protective agents. Galinski (1995) reported on a novel biotechnological process called "bacterial milking," which deals with production of ectoines and hydroxyectoines using extremely halotolerant Halomonas elongata. Ectoine and ectoine derivatives have also been patented as moisturizers in cosmetics for the care of aged, dry, or irritated skin (Motitschke et al., 2000). Another promising application is the use of ectoine as stabilizers in the polymerase chain reaction (PCR) (Sauer and Galinski, 1998).

\section{Biopolymers}

Several biopolyners have been developed from halophilic microorganisms. These include biosurfactants, exopolysaccharides, and bioplastics.

Biosurfactants enhance the remediation of oil-contaminated soil and water. By decreasing surface tension, they increase the solubility and thus the mobility of hydrophobic hydrocarbons, which may promote degradation. Biosurfactant-producing halophilic microorganisms may therefore play a significant role in the accelerated remediation of oil-polluted saline environments. Hack et al. (2000) reported promising results in hydrocarbon pollution control in marine biotopes in closed systems, such as oil storage tanks, and several studies indicated potential for pollution treatment in marine environments or coastal areas. New biosurfactants (trehalose lipids), produced by marine rhodococci during cultivation on $n$-alkanes, could become promising surface-active agents for in situ bioremediation of cold marine environments (Yakimov et al., 1999). Unfortunately, the production cost of biosurfactants is about 3-10 times higher than that of the conventional chemical compounds, which is too expensive for microbial enhanced oil recovery (MEOR) (Desai and Banat, 1997).

Exocellular polymeric substances are also called exopolysaccharides (EPS) (Weiner et al., 1995). These substances can also be derived from halophytic microorganisms and are of interest for MEOR. The desirable properties of EPS include high melting temperatures, pseudoplasticity, and resistance to salt, color, and thermal degradation. EPS are often used as emulsifiers and mobility controllers. Active emulsification of petroleum has been noted for 6 strains, close to Halobacterium salinarum, Haloferax volcanii, and Halobacterium distributum (Kulichevskaya et al., 1992).

Polyhydroxyalkanoates (PHA) are intracellularly accumulated bacterial storage compounds. These biodegradable plastics that have properties comparable to those of poly- 
ethylene and polypropylene (Rodriguez-Valera and Lillo, 1992; Steinbücel et al., 1997). Such biodegradable plastics could replace oil-derived thermoplastics in some applications. Haloferax mediterranei accumulates large amounts (up to $60 \%$ of cell dw) of polyhydroxy butyric acid (PHB). PHB production can be enhanced to about $6 \mathrm{~g} / 1 \mathrm{using}$ phosphate limitation and starch, a cheap substrate, as the carbon source (Rodriguez-Valera and Lillo, 1992). PHB recovery is simplified because the exposure of the halophile to low salt concentrations causes cell lysis (Nieto et al., 2000). In addition, this type of halophile can be cultivated easily in a simple saline open pond without risk of contamination. Recently, an extremely halophilic archaeon, isolated from an Egyptian saline soil, was reported to accumulate PHB as intracellular granules with an amount of about $53 \%$ of its cell dry weight (Hezayen et al., 2000). The substrates used were $n$-butyric acid and sodium acetate.

\section{Microbial Leaching (Biohydrometallurgy)}

Biohydrometallurgy using autotrophs extremophiles has made significant advances in development as a commercially viable technology for processing sulphide ores. Due to its environmentally friendly nature, biohydrometallurgy should come to replace many pyrometallurgical ore extraction methods in the near future.

Bioleaching has future potential for remediation of heavy metals contaminated materials (Krebs et al., 1997; Haddadin et al., 1995). The process has no routine treatment, hence leaching processes using autotrophic or heterotrophic extremophiles may be considered for environmental clean ups. Biohydrometallury's advantages over other techniques include low capital and energy costs, high flexibility, ability to be used on site, lack environmental pollution, and a shorter set-up time frame than competing approaches. Bioprocesses have been determined as being one-third to one-half the cost of conventional chemical and physical remediation technologies.

Chirpa et al. (1998) has described the new technology of electrobioleaching employing the principles of applying DC potentials to promote mineral dissolution and growth of Thiobacillus ferrooxidans. Some metals such as copper, uranium, and gold can be recovered from the ores by the process called biomining. This process is based on the activity of chemoautolithotrophic bacteria. These bacteria can grow in highly acidic environments and are able to utilize either sulfur or iron as their energy source. For example, Thiobacillus ferrooxidans has been employed to enhance copper and gold recovery from the ores (Rawlings, 1998). One of the limitations of this process is that of achieving high microbial growth rates. However, ferric iron (Sugio et al., 1985) and essential growth requirements (Touvinen et al., 1971) have been used to improve efficiency of the metal recovery from ores.

Microbial leaching is considered to be a simple and effective process for extracting precious metals from low-grade ores and mineral concentrates. Remediation using bioleaching has an economic advantage because it involves low capital and energy costs, high flexibility, and on-site application, and it does not cause environmental pollution. In addition, microbial leaching serves as a means for remediation of mining sites, treatment of mineral industrial waste products, detoxification of sewage sludge, and recovery of heavy metals from soils and sediments (Bosecker, 2001).

Chirpa et al. (1998) has suggested that fundamental research should be directed toward heterotrophic leaching and/or beneficiation of silicate, carbonate, and oxide ores. Additional research is required in microbiology and the interaction of biologists with metallurgical engineers. There should be more comprehensive study of microbial com- 
position bioheap systems and stirred-tank bioreactors. There is a need to define and understand potential interactions among components of microflora in bioreactors to improve bioleaching and mineral biooxidation. Rapid, accurate, and simple techniques for monitoring the microbial activity in bioleach/mineral biooxidation systems are needed for control of these processes by operators. New types of reactors, such as vat-type systems that permit bioleaching and effective handling of whole ore particles in the 10-mesh size range, are required. New materials for high temperature, highly corrosive conditions that are relatively low cost are required. Industrially applicable technology for heterotrophic leaching of metal oxides, carbonates, and silicates should be explored (Brierley and Brierley, 2001).

\section{Petroleum Contaminant Removal}

Petroleum is an important energy source in industry and daily life. The annual consumption of petroleum has been increasing in the last several years. With an increasing frequency of petroleum transportation and use, the probability of potential accidental release of petroleum into the environment is also increasing. Nowadays, the occurrence of oil spills on soil and in oceans is a matter of concern. In this regard, researchers are continuously investigating the fate of petroleum hydrocarbons in the marine environment and on land with an overall aim of developing effective biotechnologies for the bioremediation of spilled oil.

\section{Hydrocarbons}

The application of bioremediation as an alternative remediation technology is becoming the technique of choice for environmental professionals. This method offers superior benefits not found in other remediation processes. Biodegradation of petroleum hydrocarbons varies with the chemical structure and molecular weight of hydrocarbon molecules. The chemical structure of organic pollutants has significant influence on the extent and rate of their biodegradation (Alexander, 1981).

Extremophiles have also been utilized for the microbial degradation of crude oil and refined petroleum pollutants. Foght and McFarlane (1999) have discussed the growth of extremophiles on petroleum hydrocarbon. Some potential applications are those related to molecular genetics of polycyclic aromatic hydrocarbon degradation by bacteria. Specific studies have focused on the factors that control degradation and methods to enhance the ability of bacteria to degrade such pollutants in the environment. Foght and Westlake (1996) have isolated bacterial strains from the environment and studied the mutation of their plasmid-borne and/or chromosomal genes. April et al. (2000) have studied the process of crude oil degradation by mixed populations, pure cultures, and genetic mutants. They demonstrated the loss of parent compounds and analyzed the products of bacterial attack on crude oils using gas chromatography, mass spectrometry, and radiorespirometry. New studies in this area involve biodegradation of hydrocarbon contaminated under cold Antarctica conditions (Aislabie et al., 2000).

Most bacteria that are capable of degrading petroleum hydrocarbon s have been isolated from deep ocean environments. However, their roles in the bioremediation process are virtually unknown. Yakimov et al. (1999) isolated the Alcanivorax group from the North Sea as biosurfactant-producing and $n$-alkane-degrading marine bacteria. These bacterial strains were isolated from a variety of marine environments, including oil spill contaminated sites. During growth on $n$-alkanes, Alcanivorax borkmensis produces biosurfactants that are shown to be glucose lipids (Abraham et al., 1998). Genus Alcanivorax 
seems to play a major role in the first step of crude oil biodegradation in the marine environment (Harayama et al., 1999). However, information on the growth characteristics of Alcanivorax are still very limited. Therefore researchers are currently investigating the nutrient requirements of Alcanivorax coupled with investigations into the alkane-degradation pathways and gene analysis. They use phylogenetic identification and quantification by the technique called fluorescence in situ hybridization (FISH) (Amann et al., 1995). These investigations are performed with the overall aim to achieve complete and rapid biodegradation of alkanes. Harayama et al. (1999) observed that bacteria belonging to the genus Alcanivorax are important for the biodegradation of petroleum, especially under bioremediation conditions.

Al-Maghrabi et al. (1998) reported rapid degradation of the crude oil using thermophilic bacteria. The same specie of these thermophilic bacteria was found to survive in saline environments. Oil spills have been successfully bioremediated in marine, Arctic, and Antarctic environments (Delille et al. 1998; Margesin and Schinner, 1999). A new halo- and thermotolerant Streptomyces albaxialis was found that degraded crude oil and petroleum products even in the presence of $30 \%$ (w/v) $\mathrm{NaCl}$ (Kuznetsov et al. 1992). Zvyagintseva et al. (1995) isolated an extremely halophilic Archaea (Haloferax mediterranei) able to grow at $10-25 \%(\mathrm{w} / \mathrm{v}) \mathrm{NaCl}$; the same specie was also reported to utilize oil as the sole carbon source (Kulichevskaya et al. 1992) obtained for the first time as an isolate of the Halobacterium group from salt-rich stratum fluids of an oil deposit. The strain degraded $n$-alkanes with a $\mathrm{C}_{10}-\mathrm{C}_{30}$ composition in the presence of $30 \%(\mathrm{w} / \mathrm{v})$ $\mathrm{NaCl}$.

However, the use of bioremediation is still unproven and has some limitations when it is employed for specific problems. Few of the previous studies have reported that some chemical compounds are not biodegradable, need extensive monitoring, may involve potential production of toxic byproducts, and require strong qualitative scientific support.

\section{New Findings}

\section{Heavy Metal Recovery}

Recent findings at Princeton University indicate a newly discovered form of the bacterium Thermus sp. isolated from a groundwater sample (Onstott, 2001). This microbe is moderately tolerant to radiation effects, grows anaerobically, and in the mine environment interacts with forms of iron, chromium, cobalt, and uranium, forms of elements that often occur in contaminated soils. None of the other forms previously studied have shown this metabolic versatility, despite previous studies on the physiology and genetics of the microbe for nearly 3 decades. Two strains of thermophilic bacteria belonging to the Bacillus family were isolated from a hot water stream and used to remove strontium from aqueous stream systems (Chalaal and Islam, 2001). These bacteria were able to concentrate strontium in one side of a two-compartment bioreactor. Immobilization of heavy metals using sulfide-producing microorganisms has been reported as an effective means of treating some metals-contaminated sites (Crawford and Crawford, 1996).

\section{Future Research Interests}

Although several research findings have explored some of the unique features of extremophiles, some physiological and metabolic characteristics of these microbes in relation to their growth environment still need further study. 
Extremophiles such as anaerobic bacteria possess metabolic activities for biodegrading a range of pollutant chemicals, including aromatic, halogenated aromatic, and halogenated alkene compounds. In order to utilize anaerobic bacteria in extreme environments, it is necessary to understand their physiology and effects the environment may have on the metabolism of the bacteria of interest.

Presently, a majority of commercial applications of bioremediation depend upon indigeneous microorganisms, and most are employed for hydrocarbon-contaminate d sites. The use of genetically engineered microorganisms for remediation of some selected industrial pollutants such as trichloroethane (TCE) will gain an increased role in the coming years.

Impending bioremediation development programs should continue to dwell on isolation and characterization of superior and novel microbes to degrade halocarbons, genetic engineering of hard to degrade compound pathways, optimization of conditions for growth and activity of such microbes, and design and testing of field pilot systems.

At present, most of the biotechnological potential applications of metal/microorganism interactions are in the bioleaching of ores, bioremediation of metal-polluted sites, and mineralization of polluting organic matter. Further development on the microbial interactions with metals need some attention for efficient future exploitation of this technology. Genetic improvement of metal solubilizing microorganisms, whether by mutation and selection or by genetic engineering, will permit bioremediation processes to be improved. Intensive inter-disciplinary collaborations in basic and applied research will be beneficial for development of more effective applications.

Halophilic extremozymes have a potential in applications that is expected to increase the amount of crude extracted from oil wells. The shortcomings in perfecting manufacturing techniques, and the reluctance of industries to change systems that are in place and work reasonably well, could limit the promotion of new extremozymes into commercial use. However, future use looks inevitable because there are numerous advantages that will eventually bring about acceptance.

Extremophiles are not cultivatable under conventional laboratory culture conditions, but may offer a wealth of valuable bioproducts, ranging from bioactive small molecules to unique biopolymers and enzymes. To overcome the limitation of cultivating extremophiles on a production scale, researchers have developed a unique production-scale bioreactor capable of continuous operation at extreme temperatures and pressures. Further developmental work in this direction needs to be done because the demand is growing at an exponential rate.

\section{References}

Abraham, W. R., H. Meyer, and M. Yakimov. 1998. Novel glycine containing glucolipids from the alkane using bacterium Alcanivorax borkumensis. Biochim. Biophys. Acta 1393:57-62.

Adams, M. W. W., and R. M. Kelly. 1995. Enzymes isolated from microorganisms that grow in extreme environments. Chemical and Engineering News 73(51):32-42.

Adams, M. W. W., and R. M. Kelly. 1998. Finding and using hyperthermophilic enzymes. TIBTECH, 16:329-332.

Adams, M. W. W., F. B. Perler, and R. M. Kelly. 1995. Extremozymes. Expanding the limits of biocatalysis. Bio/technology 13:662-668.

Aislabie, J., J. Foght, and D. Saul. 2000. Aromatic hydrocarbon-degrading bacteria isolated from soil near Scott Base, Antarctica. Polar Biol. 23:183-188

Al-Maghrabi, I. M. A., A. A. Bin Aqil, M. R. Islam, and O. Chalaal. 1998. Use of thermophilic bacteria for bioremediation of petroleum contaminants. Energy Sources 21:17-29. 
Alexander, M. 1981. Biodegradation of chemicals of environmental concern. Science 211:132-138.

Amann, R., W. Ludwig, and K. H. Schleifer. 1995. Phylogenetic identification and in situ detection of individual microbial cells without cultivation. Microbiological Reviews 59:143-169.

April, T. M., J. M. Foght, and R. S. Currah. 2000. Hydrocarbon-degrading fungi isolated from flare pit soils in northern and western Canada. Can. J. Microbiol. 46:38-49.

Bosecker, K. 2001. Microbial leaching in environmental clean-up programmes. Hydrometallurgy 59:245-248.

Brierley, J. A., and C. L. Brierley. 2001. Present and future commercial applications of biohydrometallurgy. Hydrometallurgy 59:233-239.

Brock, T. D., K. M. Brock, R. T. Belly, and R. L. Weiss. 1972. Sulfolobus: A new genus of sulfuroxidizing bacteria living at low $\mathrm{pH}$ and high temperature. Arch. Microbiology 84:54-68.

Brown, M. R. 1997. The identification of bacteria pure culture from and analysis of the elemental and structural composition of a nestide taken from the R. M. S. Titanic. B.Sc (Hans) thesis, Dalhousie University, Halifax, Canada.

Chalaal, O., and M. R. Islam. 2001. Integrated management of radiactive strontium contamination in aqueous stream systems. J. Environ. Management 61:51-59.

Chirpa, S., J. M. Mudak, and K. A. Natarajan. 1998. Electrobioleaching of sphalerite floatation concentrate. Minerals Engineering 11:783-788.

Clark, T. R., F. Baldi, and G. J. Olson. 1993. Coal depyritization by the thermophilic archaeon Metallosphaera sedula. Appl. Environ. Microbiol. 59:2375-2379.

Crawford, R. L., and D. L. Crawford (ed.). 1996. Bioremediation: Principles and Applications, Cambridge: University Press.

Delille, D., A. Bassères, and A. A. Dessommes. 1998. Effectiveness of bioremediation for oilpolluted Antarctic seawater. Polar Biol 19:237-241.

Desai, J. D., and I. M. Banat. 1997. Microbial production of surfactants and their commercial potential. Microbiol. Mol. Biol. Rev. 61:47-64.

Ehrlich, H. L. 2001. Past, present, and future of biohydrometallurgy. Hydrometallurgy 59:127-134.

Foght, J. M., and D. M. McFarlane. 1999. Growth of Extremophiles on Petroleum. In Enigmatic Microorganisms and Life in Extreme Environments, J. Seckbach (ed.). Dordrecht, Netherlands: Kluwer Academic Publishers, pp. 527-538.

Foght, J. M., and D. W. S. Westlake. 1996. Transposon and spontaneous deletion mutants of plasmid-borne genes encoding polycyclic aromatic hydrocarbon degradation by a strain of Pseudomonas fluorescens. Biodegradation 7:353-366.

Galinski, E. A. 1995. Osmoadaptation in bacteria. Advances in Microbiology and Physiology 37:273-328.

Galinski, E. A., and B. J. Tindall. 1992. Biotechnological Prospects for Halophiles and Halotolerant Micro-organisms. In Molecular Biology and Biotechnology of Extremophiles, R. H. Herbert and R. J. Sharp (eds.). Glasgow: Blackie, pp. 76-114.

Garabito, M. J., M. C. Marquez, and A. Ventosa. 1998. Halotolerant Bacillus diversity in hypersaline environments. Canadian Journal of Microbiology 44:95-102.

Hack, C. J., Woodley, J. M., Lilly, M. D., and Liddell, J. M. 2000. Design of a control system for biotrasis formation of toxis substrates: Toluene hydroxylation by pseudomonas putida UV4. Enzyme and Microbial Technology 26:530-536.

Haddadin, J., C. Dagot, and M. Fick. 1995. Models of bacterial leaching. Reviews: Enzyme and Microbial Technology 17:290-305.

Harayama, S., H. Kishira, Y. Kasai, and K. Shutsubo. 1999. Petroleum biodegradation in marine environments. Journal of Molecular Microbiology and Biotechnology 1:63-70.

Hezayen, F. F., B. H. A. Rehm, R. Eberhardt, and A. Steinbüchel. 2000. Polymer production by two newly isolated extremely halophilic archaea: Application of a novel corrosion-resistant bioreactor. Appl. Microbiol. Biotechnol. 54:319-325.

Horikoshi, K. 1999. Alkaliphiles, Tokyo: Harwood Academic Publishers.

Irgens, R. L., J. J. Gosink, and J. T. Staley. 1996. Polaromonas vacuolata, nov. gen et sp., a psychrophilic, marine, gas vacuolate bacterium from Antarctica. Int. J. Syst. Bacteriol. 46: 822-826. 
Krebs, W., C. Brombacher, P. P. Bosshard, R. Bachofen, and H. Brandl. 1997. Microbial recovery of metals from solids. FEMS Microbiology Reviews 20:605-617.

Kulichevskaya, I. S., E. I. Milekhina, I. A. Borzenkov, I. S. Zvyagintseva, and S. S. Belyaev. 1992. Oxidation of petroleum hydrocarbons by extremely halophilic archaebacteria. Microbiology 60:596-601.

Kuznetsov, V. D., T. A. Zaitseva, L. V. Vakulenko, and S. N. Filippova. 1992. Streptomyces albiaxalis sp. nov.: A new petroleum hydrocarbon-degrading species of thermo- and halotolerant Streptomyces. Microbiology 61:62-67.

Madigan, M. T., J. M. Martinko, and J. Parker. 1997. Brock Biology of Microorganisms, 8th ed., Englewood Cliffs, NJ: Prentice Hall.

Margesin, R., and F. Schinner. 1999. Biological decontamination of oil spills in cold environments. J. Chem. Technol. Biotechnol. 74:381-389.

McAlister, R. 1998. Manufacturing Sustainable Prosperity. In Hydrogen Today, American Hydrogen Association. Vol. 8, No. 1. pp. 1-34.

Miyamoto, K. 1997. Renewable Biological Systems for Alternative Sustainable Energy Production, FAO Agricultural Services Bulletin 128, Osaka University, Japan.

Motitschke, L., H. Driller, and E. Galinski. 2000. Ectoin and Ectoin derivatives as moisturizers in cosmetics. US Patent 060071.

Nieto, J. J., C. Vargas, and A. Ventosa. 2000. Osmoprotection mechanism in the moderately halophilic bacteria Halomonas alongata. Recent Research and Development in Microbiology 4:43-54.

Onstott, T. C. 2001. Microbial Diversity in Hot Zone: South African Microbiology Project, Department of Geosciences, Geomicrobiology Research Group's website, Princeton University, Princeton, NJ. http://geoweb.princeton.edu/people/faculty/enstott/research.html

Palumbo, J., and J. Zhou. 1996. Amazing Microbes, URL www.ornl.gov

Peeples, T. L., and R. M. Kelly. 1995. Bioenergetic response of the extreme thermoacidophile Metallosphaera sedula to thermal and nutritional stress. Appl. Environ. Microbiol., 61:2314 2321.

Raven, N., N. Ladwa, D. Cossar, and R. Sharp. 1992. Continuous culture of the hyperthermophilic archaeum Pyrococcus furiosus. Appl. Microbiol. Biotech. 38:263-267.

Rawlings, D. E. 1998. Industrial practice and the biology of leaching of metals from ores: The 1997 Pan labs lecture. J. Indust. Microbiol. Biotech. 20:268-274.

Rinker, K. D., C. J. Han, M. W. W. Adams, and R. M. Kelly. 1999. Cultivation of Hyperthermophilic and Extremely Thermoacidophilic Microorganisms. In Manual of Industrial Microbiology and Biotechnology, 2nd ed. A. L. Demain and J. E. Davis (eds.), Washington, D.C.: ASM Press pp. 119-136.

Robertson, D. E., E. J. Mathurs, R. V. Swarsy, B. L. Marrs, and J. M. Short. 1996. The discovery of new biocatalysts from microbial diversity. SIM News 46:3-8.

Rodriguez-Valera, F., and J. G. Lillo. 1992. Halobacteria as producers of polyhydroxyalkanoates. FEMS Microbiol. Rev. 103:181-186.

Sauer, T., and E. A. Galinski. 1998. Bacterial milking: A novel bioprocess for production of compatible solutes. Biotechnology Bioengineering 57:306-313.

Schicho, R. N., K. Ma, M. W. W. Adams, and R. M. Kelly. 1993. Bioenergetics of sulfur reduction in the hyperthermophilic archaeon Pyrococcus furiosus. Journal of Bacteriology, 175:18231830.

Steinbüchel, A., B. Füchtenbusch, V. Gorenflo, S. Hein, R. Jossek, S. Langenbach, and B. H. A. Rehm. 1997. Biosynthesis of polyesters in bacteria and recombinant organisms. Polymer Degrad. Stabil. 59:177-182.

Sugio, T., C. Domatsu, O. Munakata, T. Tano, and K. Imai. 1985. Role of ferric ion-reducing system in sulfur oxidation of Thiobacillus ferrooxidans. Appl. Environ. Microbiol. 49:14011406.

Tayal, A., R. M. Kelly, and S. A. Khan. 1997. Viscosity reduction of hydraulic fracturing fluids through enzymatic hydrolysis. Journal of Society of Petroleum Engineering 2(2):204-212. 
Touvinen, O. H., S. I. Niemela, and H. G. Gyllenberg. 1971. Effect of mineral nutrients and organic substances on the development of the Thiobacillus ferrooxidans. Biotechnology and Bioengineering 13:517-527.

Ventosa, A., J. J. Nieto, and Oren. 1998. Biology of moderately halophilic aerobic bacteria. Microbiology and Molecular Biology Reviews 62:504-544.

Weiner, R., S. Langille, and E. Quintero. 1995. Structure, function and immunochemistry of bacterial exopolysaccharides. Journal of Industrial Microbiology 15:339-346.

Wells, W. S., and H. Mann. 1997. Microbiology and Formation of Microbially Assisted Rusticles from the R.M.S. Titanic, B.Sc. (Hons) thesis, St. Mary's University, Halifax, Canada.

Wells, W. S., and H. Mann. 1997. Microbiology information of rustides from the R. M. S. Titanic. Resource and Environmental Biotechnology 1:271-281.

Wiegel, J. 1999. Microbial Biosystems: New Frontiers. Proceedings of the 8th International Symposium on Microbial Ecology, C. R. Bell, M. Brylinsky, and P. Johnson-Green (eds.), Atlantic Canada Society for Microbial Ecology, Halifax, Canada.

Woodward, J., M. Orr, K. Cordray, and E. Greenbaum. 2000. Biotechnology: Enzymatic production of biohydrogen. Nature, 405:1014.

Yakimov, M. M., L. Guiliano, V. Bruni, S. Scarfi, and P. N. Golyshin. 1999. Characterization of Antarctic hydrocarbon-degrading bacteria capable of producing bioemulsifiers. Microbiologica (Pavia) 22:249-256.

Zvyagintseva, I. S., S. S. Belyaev, I. A. Borzenkov, N. A. Kostrikina, E. I. Milekhina, and M. V. Ivanov. 1995. Halophilic archaebacteria from the Kalamkass oil field. Microbiology 64:67-71. 